\title{
Biphasic Insulin Aspart 30 Therapy in Insulin-Naïve and Insulin-Experienced Patients with Type 2 Diabetes: Results from the Jordanian Subgroup of the $A_{1}$ chieve Study
}

\author{
Jihad Haddad ${ }^{*}$, Fares H. Haddad ${ }^{2}$, Rashad Nasser ${ }^{3}$, Abdel-Ellah Al-Shudifat ${ }^{1}$, \\ Firas Abbas Annabi ${ }^{4}$, Levent Sandalci ${ }^{5}$, Moawia Al-Kilani6 \\ ${ }^{1}$ Prince Hamzah Hospital, Amman, Jordan \\ ${ }^{2}$ King Hussein Medical Center, Amman, Jordan \\ ${ }^{3}$ Italian Hospital, Amman, Jordan \\ ${ }^{4}$ Islamic Hospital, Amman, Jordan \\ ${ }^{5}$ Novo Nordisk Business Area Near East, Istanbul, Turkey \\ ${ }^{6}$ Jabal Al Zayton Hospital, Zarqa, Jordan \\ Email: " haddad jihad@yahoo.gr
}

Received 10 September 2014; revised 8 October 2014; accepted 3 November 2014

Copyright (C) 2014 by authors and Scientific Research Publishing Inc.

This work is licensed under the Creative Commons Attribution International License (CC BY). http://creativecommons.org/licenses/by/4.0/

c) (i) Open Access

\section{Abstract}

Objective: To analyse the safety and effectiveness of biphasic insulin aspart 30 (BIAsp 30) in a Jordanian subgroup of the 24-week, non-interventional A1chieve study. Methods: A total of 509 Jordanian patients with type 2 diabetes (392 insulin-naïve and 117 insulin-experienced) starting BIAsp30, alone or in combination with oral glucose-lowering drugs, were included. Safety and effectiveness outcomes were analysed over 24 weeks. Results: Patients had a mean age of 55.8 years, body mass index of $28.8 \mathrm{~kg} / \mathrm{m}^{2}$ and diabetes duration of 9.4 years at baseline. Two serious adverse drug reactions of hypoglycaemia were reported. The proportion of patients who reported major hypoglycaemic events decreased $(2.4 \%$ at baseline vs. $0.2 \%$ at Week $24, p=0.0039)$. The proportion of patients reporting overall hypoglycaemia increased marginally $(6.3 \%$ at baseline vs. $9.9 \%$ at Week $24, p=0.0378$ ), primarily attributed to a rise in minor and nocturnal hypoglycaemia reported in insulin-naïve patients. From baseline to Week 24, the mean \pm SD glycated haemoglobin A1c level decreased from $9.8 \% \pm 1.4 \%$ to $7.4 \% \pm 0.9 \%(p<0.001)$. Significant reductions after 24 weeks were also noted in the mean fasting plasma glucose, postprandial plasma glucose, lipids,

*Corresponding author.

How to cite this paper: Haddad, J., et al. (2014) Biphasic Insulin Aspart 30 Therapy in Insulin-Naïve and Insulin-Experienced Patients with Type 2 Diabetes: Results from the Jordanian Subgroup of the $\mathrm{A}_{1}$ chieve Study. Journal of Diabetes Mellitus, 4, 379-387. http://dx.doi.org/10.4236/jdm.2014.44051 
systolic blood pressure and quality of life (all $p<0.001$ ), while the mean body weight increased by $1.8 \pm 6.5 \mathrm{~kg}(\mathrm{p}<0.001)$. Conclusion: Overall, BIAsp 30 therapy was well-tolerated and resulted in improved glycaemic control in this Jordanian subgroup over 24 weeks.

\section{Keywords}

Biphasic Insulin Aspart 30, Jordan, Type 2 Diabetes, $A_{1}$ chieve, Clinical Practice

\section{Introduction}

The burgeoning crisis of type 2 diabetes (T2D) has imposed a severe strain on the healthcare resources of developing countries such as Jordan [1]. In 2012, Jordan reported a diabetes prevalence of 8.73\% [2]. Data from the national Behavioural Risk Factor Surveillance System in 2004 [3] disclosed an increased prevalence of diabetes risk factors, such as obesity, and a high proportion of participants with undiagnosed diabetes. Also, an analysis involving 917 T2D patients in Jordan revealed that poor glycaemic control was chiefly linked to the long duration of T2D and lack of adherence to recommended self-care behaviours [4]. Indeed, improving T2D awareness and treatment adherence of patients are among the prime goals of T2D management in Jordan.

International treatment guidelines [5] recommend maintaining glycated haemoglobin $\mathrm{A}_{1 \mathrm{c}}\left(\mathrm{HbA}_{1 \mathrm{c}}\right)$ levels at $<7.0 \%$, fasting plasma glucose (FPG) at $<130 \mathrm{mg} / \mathrm{dL}$ and postprandial plasma glucose (PPPG) at $<180 \mathrm{mg} / \mathrm{dL}$ to avoid the risk of incurring long-term diabetic complications. Physicians are further advised to appropriately intensify therapeutic regimens to maintain blood glucose at the recommended levels [5]. However, inadequate monitoring of disease progression and concerns about hypoglycaemia, injections and weight gain may inhibit patients and physicians from following these recommendations. Even so, T2D patients will eventually require supplementation of both basal and prandial insulin owing to the gradual loss of beta-cell function [6]. Premixed insulins, constituting a mixture of rapid-acting insulin with a basal version, were developed to help remedy the endogenous insulin deficit.

Biphasic insulin aspart 30 (BIAsp 30) is a premixed insulin analogue consisting of 70\% protaminated insulin aspart (IAsp) and 30\% rapid-acting IAsp [7]. The longer-acting protaminated component addresses basal insulin requirements and rapid-acting IAsp addresses the prandial insulin deficit. BIAsp 30 therapy is associated with low incidences of major and nocturnal hypoglycaemia [8] [9] and is known to effectively reduce high blood glucose [10].

Often, healthcare policy design and implementation is hampered by a dearth of local clinical data. Observational studies, such as $A_{1}$ chieve, conducted across 28 countries [11], could provide a key pool of data that can aid in informing local policies and clinical practice guidelines.

The $\mathrm{A}_{1}$ chieve study was non-interventional in nature and aimed to gather information on the safety and effectiveness of insulin analogues in routine healthcare in different countries. This Jordanian sub-analysis aimed to document the safety and effectiveness of BIAsp 30 therapy in local practice and also to examine the current status of T2D management in Jordan.

\section{Patients and Methods}

\subsection{Study Design}

The $\mathrm{A}_{1}$ chieve study was an open-label, 24-week, prospective study of the clinical safety and effectiveness of BIAsp 30 (NovoMix $30^{\circledR}$, Novo Nordisk A/S, Denmark), insulin detemir (Levemir ${ }^{\circledR}$, Novo Nordisk A/S, Denmark) and IAsp (NovoRapid ${ }^{\circledR}$, Novo Nordisk A/S, Denmark), as monotherapy or in combination with oral glucose-lowering drugs (OGLDs), in the treatment of T2D [11]. Here, the data of Jordanian patients with T2D who started BIAsp 30 therapy (with or without concomitant OGLDs) based on their physicians' decisions was evaluated. The methods and procedures of the $\mathrm{A}_{1}$ chieve study have been described in detail elsewhere [11].

\subsection{Patient Population}

Patients with T2D who started BIAsp 30 therapy within 4 weeks prior to the study were recruited between No- 
vember 2009 and December 2010 from 32 centres in Jordan. Pregnant or lactating women as well as those who had the intention of becoming pregnant within the following 6 months were excluded. Patients who had taken any of the Novo Nordisk insulin analogues (BIAsp 30, IDet and IAsp) over 4 weeks prior to the start of the study were excluded as were those with known allergies or hypersensitivity to any of the study drugs or excipients. Appropriate ethical review board approval in Jordan was obtained and patients gave written informed consent for the use of their data at the time of initiation of injectable therapy (baseline).

\subsection{Outcomes}

The primary outcome was the incidence of serious adverse drug reactions (SADRs), including major hypoglycaemic events, from baseline to Week 24. Other outcomes included the change in the proportion of patients reporting hypoglycaemic events (overall, major, minor and nocturnal) in the 4 weeks prior to baseline and Week 24, and the change from baseline to Week 24 in $\mathrm{HbA}_{1 \mathrm{c}}$, FPG, PPPG, lipid profile, systolic blood pressure (SBP), body weight and quality of life (QoL). Only post-lunch PPPG values are presented for this subgroup because of the low number of patients that reported post-breakfast PPPG values $(n=38)$.

Health-related quality of life (QoL) was assessed at baseline and Week 24 using the EQ-5D questionnaire (comprising a visual analogue scale rated from 0 [worst imaginable health] to 100 [best imaginable health] and five health dimensions). Physicians assessed all parameters at routine clinical visits and recorded the data in standardized case report forms.

\subsection{Statistical Analyses}

Statistical analyses were performed for the entire subgroup and were also stratified by pre-study insulin exposure, i.e., insulin-naïve and insulin-experienced patients. The changes in $\mathrm{HbA}_{1 \mathrm{c}}$, FPG, PPPG, SBP, body weight, lipid profile and QoL were analysed using a paired t-test with baseline and Week 24 values. The change from baseline to Week 24 in the proportion of patients reporting at least one hypoglycaemic event was analysed using McNemar's test. For all tests, a significance level of 5\% was applied. The analyses were performed using SAS version 9.1 .3

\section{Results}

\subsection{General Characteristics}

A total of 509 patients (392 insulin-naïve and 117 insulin-experienced) started BIAsp 30 therapy at baseline in Jordan. Demographic and baseline characteristics are presented in Table 1 . These patients had a mean \pm SD age of $55.8 \pm 10.9$ years and a mean body mass index of $28.8 \pm 5.2 \mathrm{~kg} / \mathrm{m}^{2}$. The mean duration of T2D was $9.4 \pm 5.1$ years in this subgroup.

At pre-study, $59.0 \%$ of patients in the entire subgroup were taking 2 OGLDs and $96.7 \%$ were on metformin. At baseline, the majority of patients switched to 1 OGLD (78.0\%) and continued metformin use (Table 1).

\subsection{Physicians' Reasons for Starting BIAsp 30 Therapy}

A total of 499 patients (98.0\%) started BIAsp 30 to improve glycaemic control in the entire subgroup as reported by their physicians. Among insulin-naïve patients, the major reason for starting BIAsp 30 therapy was to improve glycaemic control (99.5\%), while among insulin-experienced patients, the major reasons were to improve glycaemic control (93.2\%) and to try a new insulin (49.6\%).

\subsection{Insulin Dose and Frequency of Administration}

The mean total insulin dose and frequency of administration is presented in Table 2.

The mean insulin dose by weight at pre-study was $0.58 \pm 0.26 \mathrm{U} / \mathrm{kg}$ in insulin-experienced patients. At baseline, insulin-experienced patients had a mean starting dose of $0.70 \pm 0.24 \mathrm{U} / \mathrm{kg}$, which was titrated up to $0.75 \pm$ $0.23 \mathrm{U} / \mathrm{kg}$ at Week 24 .

Insulin-naïve patients started on $0.49 \pm 0.20 \mathrm{U} / \mathrm{kg}$ of BIAsp 30 at baseline, which was titrated up to $0.76 \pm$ $0.33 \mathrm{U} / \mathrm{kg}$ at Week 24. 
Table 1. Baseline demographics and characteristics.

\begin{tabular}{|c|c|c|c|}
\hline Parameter & All patients & Insulin naïve & Insulin users \\
\hline N (\%) & $509(100)$ & $392(77)$ & $117(23)$ \\
\hline Gender (male/female) & $53.6 / 46.4$ & $55.6 / 44.4$ & $47.0 / 53.0$ \\
\hline Age $^{*}$, years & $55.8(10.9)$ & $55.7(10.3)$ & $56.0(12.8)$ \\
\hline Body weight ${ }^{*}, \mathrm{~kg}$ & $82.2(15.9)$ & $81.3(15.7)$ & $84.8(16.5)$ \\
\hline Body mass index ${ }^{*}, \mathrm{~kg} / \mathrm{m}^{2}$ & $28.8(5.2)$ & $28.3(4.9)$ & $30.4(5.9)$ \\
\hline Duration of diabetes ${ }^{*}$, years & $9.4(5.1)$ & $9.0(4.8)$ & $10.7(5.7)$ \\
\hline Time to insulin initiation ${ }^{*}$, years & $8.7(4.9)$ & $9.1(4.9)$ & $7.6(4.9)$ \\
\hline Duration on OGLDs ${ }^{*}$, years & $8.9(4.7)$ & $8.9(4.6)$ & $8.9(5.0)$ \\
\hline Duration on insulin", years & $1.0(2.6)$ & $0.3(1.6)^{\dagger}$ & $3.3(3.7)$ \\
\hline \multirow[t]{2}{*}{$\mathrm{HbA}_{1 \mathrm{c}}^{*}, \%$} & $9.8(1.4)$ & $9.9(1.3)$ & $9.1(1.4)$ \\
\hline & OGLDs, n (\%) & & \\
\hline Metformin & 338 (98.0) & $279(97.6)$ & $59(100)$ \\
\hline Sulfonylurea & $66(19.1)$ & $62(21.7)$ & $4(6.8)$ \\
\hline Thiazolidinediones & $20(5.8)$ & $20(7.0)$ & $0(0)$ \\
\hline One & $269(78.0)$ & 214 (74.8) & 55 (93.2) \\
\hline Two & $57(16.5)$ & 53 (18.5) & $4(6.8)$ \\
\hline$>$ Two & $19(5.5)$ & $19(6.6)$ & $0(0)$ \\
\hline
\end{tabular}

$\mathrm{HbA}_{1 \mathrm{c}}$ : glycated haemoglobin $\mathrm{A}_{1 \mathrm{C}}$; OGLDs: oral glucose-lowering drugs. ${ }^{*}$ Data are mean (SD). ${ }^{\dagger}$ Some patients were on insulin for a short period in the past, but were not on insulin when they were enrolled into the study.

\section{Table 2. Insulin dose and frequency by pre-study therapy type.}

\begin{tabular}{|c|c|c|c|c|}
\hline & & All patients & Insulin naïve & Insulin users \\
\hline \multirow{14}{*}{ Daily dose frequency } & Pre-study, n & 117 & $0(0)$ & 117 \\
\hline & Once, n (\%) & $29(24.8)$ & $0(0)$ & $29(24.8)$ \\
\hline & Twice, n (\%) & $69(59.0)$ & $0(0)$ & $69(59.0)$ \\
\hline & Thrice, n (\%) & $19(16.2)$ & $0(0)$ & $19(16.2)$ \\
\hline & Baseline, $n$ & 506 & 390 & 116 \\
\hline & Once, n (\%) & $49(9.7)$ & $47(12.1)$ & $2(1.7)$ \\
\hline & Twice, n (\%) & 332 (65.6) & $273(70.0)$ & 59 (50.9) \\
\hline & Thrice, n (\%) & $124(24.5)$ & $70(17.9)$ & $54(46.6)$ \\
\hline & >thrice, n (\%) & $1(0.2)$ & $0(0)$ & $1(0.9)$ \\
\hline & Week 24, n & 463 & 362 & 101 \\
\hline & Once, n (\%) & $30(6.5)$ & $28(7.7)$ & $2(2.0)$ \\
\hline & Twice, n (\%) & 293 (63.3) & 241 (66.6) & 52 (51.5) \\
\hline & Thrice, n (\%) & 135 (29.2) & 89 (24.6) & $46(45.5)$ \\
\hline & >thrice, n (\%) & $5(1.1)$ & $4(1.1)$ & $1(1.0)$ \\
\hline \multirow{3}{*}{ Insulin dose, U/day } & Pre-study ${ }^{*}$ & $48.6(24.0)$ & $0(0)$ & $48.6(24.0)$ \\
\hline & Baseline $^{*}$ & 43.4 (18.3) & $39.2(15.9)$ & $57.2(19.0)$ \\
\hline & Week $24^{*}$ & $60.2(24.2)$ & $59.7(25.5)$ & $62.2(18.7)$ \\
\hline \multirow{3}{*}{ Insulin dose, $\mathrm{U} / \mathrm{kg}$} & Pre-study ${ }^{*}$ & $0.58(0.26)$ & $0(0)$ & $0.58(0.26)$ \\
\hline & Baseline $^{*}$ & $0.54(0.22)$ & $0.49(0.20)$ & $0.70(0.24)$ \\
\hline & Week $24^{*}$ & $0.76(0.31)$ & $0.76(0.33)$ & $0.75(0.23)$ \\
\hline
\end{tabular}

*Data are mean (SD). 


\subsection{SADRs and Hypoglycemia}

Two SADRs of hypoglycaemia were reported (1 event in an insulin-naïve patient and 1 event in an insulin-experienced patient); both events were considered probably related to BIAsp 30.

The incidence rate of hypoglycaemia and the proportion of patients who reported hypoglycaemic events at baseline and Week 24 are presented in Table 3. The incidence rates of overall and major hypoglycaemia appeared to decrease from baseline to Week 24 in insulin-experienced patients, associated with a significant reduction from baseline in the proportion of patients reporting these events at Week 24 (overall hypoglycaemia: 23.1\% to $11.8 \%$; major hypoglycaemia: $8.5 \%$ to $0 \%$; both $\mathrm{p}<0.05$ ).

The incidence rate of overall hypoglycaemia was 0.30 events per patient-year at baseline and 2.79 events per patient-year at Week 24 in insulin-naïve patients, corresponding to a statistically significant increase in the proportion of patients that reported overall hypoglycaemia between baseline and Week $24(1.3 \%$ to $9.4 \%$, p < $0.0001)$. The proportion of insulin-naïve patients reporting major hypoglycaemia changed from $0.5 \%$ at baseline to $0.3 \%$ at Week 24 ; however, the change was not statistically significant.

\section{5. $\mathrm{HbA}_{1 \mathrm{c}}, \mathrm{FPG}$ and PPPG}

Glycaemic parameters at baseline and Week 24 are presented in Figure 1. The mean $\mathrm{HbA}_{1 \mathrm{c}}$ level reduced significantly from $9.8 \% \pm 1.4 \%$ at baseline to $7.4 \% \pm 0.9 \%$ at Week 24 in the entire subgroup $(\mathrm{p}<0.001)$.

At Week 24, 112 patients (25.9\%) in the entire subgroup had $\mathrm{HbA}_{1 \mathrm{c}}$ levels $<7.0 \%$ compared to 6 patients (1.2\%) at baseline. Among insulin-naïve patients, the number of patients with $\mathrm{HbA}_{1 \mathrm{c}}<7.0 \%$ changed from 4 patients (1.0\%) at baseline to 76 patients (22.4\%) at Week 24 and among insulin users, from 2 patients (1.8\%) to 36 patients (39.1\%).

Statistically significant improvements at Week 24 were also noted in the mean FPG and post-lunch PPPG values in the entire subgroup $(\mathrm{p}<0.001)$.

\subsection{Body Weight, Systolic Blood Pressure and Blood Lipids}

In the entire subgroup, an increase in mean body weight from $81.4 \pm 15.0 \mathrm{~kg}$ at baseline to $83.1 \pm 12.8 \mathrm{~kg}$ at Week 24 was observed (mean change: $+1.8 \mathrm{~kg} \pm 6.5 \mathrm{~kg}, \mathrm{p}<0.001$, Table 4). The average SBP decreased from

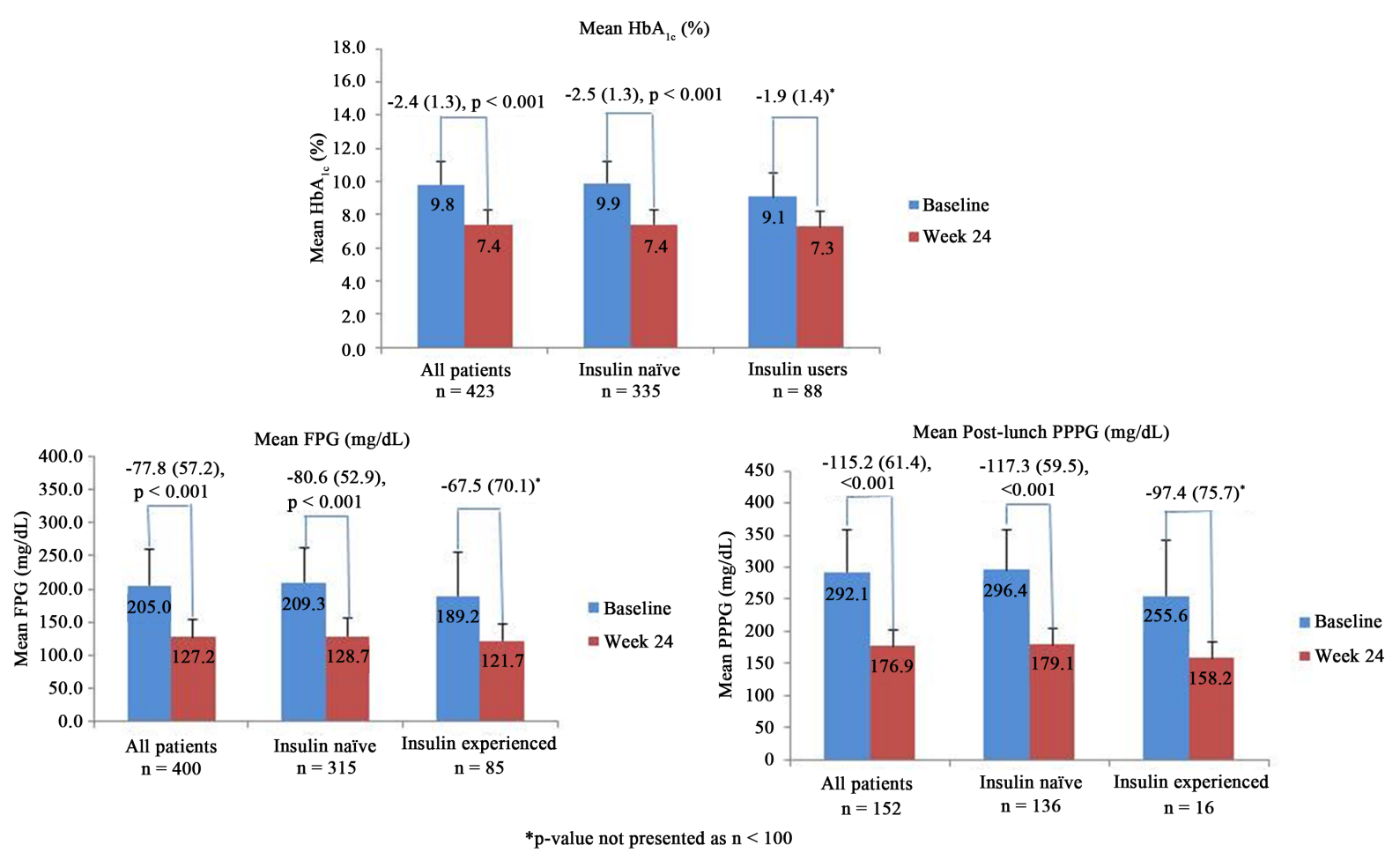

Figure 1. Glycaemic parameters at baseline and Week 24. 
Table 3. Hypoglycaemia by pre-study regimen.

\begin{tabular}{ccccc}
\hline Event per patient-year/percent with at least one event & All patients & Insulin naïve & Insulin users \\
\hline \multirow{2}{*}{ Overall } & Baseline & $1.92 / 6.3$ & $0.30 / 1.3$ & $7.33 / 23.1$ \\
& Week 24 & $3.02 / 9.9$ & $2.79 / 9.4$ & $3.82 / 11.8$ \\
& p & 0.0378 & $<0.0001$ & 0.0285 \\
Major & Baseline & $0.41 / 2.4$ & $0.07 / 0.5$ & $1.56 / 8.5$ \\
& Week 24 & $0.03 / 0.2$ & $0.04 / 0.3$ & $0.00 / 0.0$ \\
& p & 0.0039 & 0.5637 & 0.0027 \\
Nocturnal & Baseline & $0.79 / 4.1$ & $0.10 / 0.8$ & $3.11 / 15.4$ \\
& Week 24 & $1.01 / 4.7$ & $0.82 / 3.6$ & $1.66 / 8.8$ \\
& p & 0.6015 & 0.0075 & 0.1083 \\
Binor & Baseline & $1.51 / 5.3$ & $0.23 / 0.8$ & $5.78 / 20.5$ \\
& Week 24 & $2.99 / 9.7$ & $2.76 / 9.1$ & $3.82 / 11.8$ \\
& p & 0.0072 & $<0.0001$ & 0.0833 \\
\hline
\end{tabular}

p-value is from McNemar's test on the paired proportions of patients experiencing hypoglycaemia.

\section{Table 4. Body weight, SBP and blood lipids by pre-study regimen.}

\begin{tabular}{|c|c|c|c|c|}
\hline & & All patients & Insulin naïve & Insulin users \\
\hline \multirow{4}{*}{ Body weight, kg } & $n$ & 347 & 273 & 74 \\
\hline & Baseline & $81.4(15.0)$ & $80.5(14.6)$ & $84.7(16.0)$ \\
\hline & Week 24 & $83.1(12.8)$ & $82.5(12.2)$ & $85.6(14.6)$ \\
\hline & Change, $p$ & 1.8 (6.5), $<0.001$ & 2.0 (6.5), $<0.001$ & 0.8 (6.4), 0.268 \\
\hline \multirow{4}{*}{ SBP, mmHg } & $\mathrm{n}$ & 418 & 329 & 89 \\
\hline & Baseline & $137.9(16.8)$ & $137.3(16.3)$ & 139.9 (18.6) \\
\hline & Week 24 & $131.7(12.0)$ & 131.8 (11.9) & $131.3(12.3)$ \\
\hline & Change, $p$ & $-6.1(16.1),<0.001$ & $-5.5(16.1),<0.001$ & $-8.6(16.0),<0.001$ \\
\hline \multirow{4}{*}{ Total cholesterol, mmol/L } & $\mathrm{n}$ & 216 & 170 & 46 \\
\hline & Baseline & $5.5(1.1)$ & $5.6(1.1)$ & $5.2(1.0)$ \\
\hline & Week 24 & $4.9(0.7)$ & $4.9(0.6)$ & $4.8(0.7)$ \\
\hline & Change, $p$ & $-0.6(1.0),<0.001$ & $-0.7(1.1),<0.001$ & -0.4 (0.9), 0.009 \\
\hline \multirow{4}{*}{ Triglycerides, mmol/L } & $\mathrm{n}$ & 208 & 163 & 45 \\
\hline & Baseline & $2.8(1.1)$ & $3.0(1.1)$ & $2.2(1.0)$ \\
\hline & Week 24 & $2.2(0.8)$ & $2.2(0.8)$ & $2.0(0.7)$ \\
\hline & Change, $p$ & $-0.6(1.2),<0.001$ & $-0.7(1.2),<0.001$ & $-0.2(1.1), 0.149$ \\
\hline \multirow{4}{*}{ HDL cholesterol, mmol/L } & $\mathrm{n}$ & 210 & 164 & 46 \\
\hline & Baseline & $1.0(0.3)$ & $1.0(0.3)$ & $1.0(0.3)$ \\
\hline & Week 24 & $1.0(0.2)$ & $1.0(0.2)$ & $1.0(0.3)$ \\
\hline & Change, $p$ & 0.0 (0.2), 0.065 & 0.0 (0.2), 0.037 & 0.0 (0.3), 0.87 \\
\hline \multirow{4}{*}{ LDL cholesterol, mmol/L } & $\mathrm{n}$ & 215 & 168 & 47 \\
\hline & Baseline & $3.2(0.9)$ & $3.2(0.9)$ & $3.2(0.9)$ \\
\hline & Week 24 & $2.7(0.6)$ & $2.7(0.6)$ & $2.7(0.8)$ \\
\hline & Change, $p$ & -0.5 (0.9), <0.001 & $-0.5(0.8),<0.001$ & $-0.5(0.9),<0.001$ \\
\hline
\end{tabular}

HDL: high-density lipoprotein; LDL: low-density lipoprotein; SBP: systolic blood pressure. Baseline, Week 24 and change values are mean (SD). 
$137.9 \pm 16.8 \mathrm{mmHg}$ at baseline to $131.7 \pm 12.0 \mathrm{mmHg}$ at Week 24 (mean change: $-6.1 \pm 16.1 \mathrm{mmHg}, \mathrm{p}<0.001$, Table 4).

No statistically significant change was noted in the mean HDL cholesterol levels, while the mean total cholesterol, triglyceride and LDL cholesterol levels were lower at Week 24 compared to baseline in the entire subgroup ( $<<0.001$, Table 4).

\subsection{Quality of Life}

The mean QoL increased from $62.1 \pm 14.2$ points at baseline to $72.3 \pm 9.5$ points at Week 24 (mean change: $+10.2 \pm 14.7$ points, $\mathrm{p}<0.001$ ).

\section{Discussion}

This sub-analysis showed that BIAsp 30 therapy was well-tolerated in Jordanian patients with T2D and was associated with significant reductions of hyperglycaemia in both insulin-naïve and insulin-experienced patients over 24 weeks. Poor glycaemic control was apparent in the entire subgroup at baseline (mean $\mathrm{HbA}_{1 \mathrm{c}}, 9.8 \%$; FPG, $205.0 \mathrm{mg} / \mathrm{dL}$; PPPG, $292.1 \mathrm{mg} / \mathrm{dL}$ ). Even patients previously treated with other insulins for approximately 3 years had average $\mathrm{HbA}_{1 \mathrm{c}}$ levels of $9.1 \%$ at baseline. These results are consistent with baseline findings from the overall $A_{1}$ chieve cohort that also revealed high levels of blood glucose (mean $\mathrm{HbA}_{1 \mathrm{c}}$, 9.5\%) [11].

The incidence of major hypoglycaemia reduced from baseline to Week 24 in the entire Jordanian subgroup, with significantly fewer patients reporting major hypoglycaemic events after 24 weeks of BIAsp 30 therapy. The increased incidence of overall hypoglycaemia noted in the entire subgroup was primarily caused by an increase in the proportion of insulin-naïve patients reporting minor and nocturnal hypoglycaemic events. The proportion of insulin-naïve patients that reported minor hypoglycaemia also increased significantly from baseline to Week 24 in the overall $\mathrm{A}_{1}$ chieve cohort on BIAsp 30 therapy [11].

Fasting and postprandial glucose levels reduced markedly in the Jordanian subgroup following 24 weeks' treatment with BIAsp 30. The reductions in FPG and PPPG were accompanied by reductions in the $\mathrm{HbA}_{1 \mathrm{c}}$ levels in these Jordanian patients as well, triggering improvements in mean $\mathrm{HbA}_{1 \mathrm{c}}$ by $-2.5 \% \pm 1.3 \%$ in insulin-naïve patients and $-1.9 \% \pm 1.4 \%$ in insulin-experienced patients. Furthermore, 112 patients in the entire subgroup achieved the $\mathrm{HbA}_{1 \mathrm{c}}$ target level of $<7.0 \%$ by Week 24 compared to only 6 patients at baseline. These results are particularly noteworthy in the light of findings from the United Kingdom Prospective Diabetes Study that linked a $1 \%$ reduction in mean $\mathrm{HbA}_{1 \mathrm{c}}$ to a $37 \%$ risk reduction for microvascular complications and a $14 \%$ risk reduction for myocardial infarction [12].

Hypercholesterolaemia and hypertriglyceridaemia are common co-morbidities for T2D patients. A 2006 study revealed that dyslipidaemia was highly prevalent among Jordanian T2D patients (reported in over $90 \%$ of patients) and high LDL cholesterol levels were the most common form (reported in 91.5\% of patients) [13]. In this sub-analysis, Jordanian patients presented with high lipid levels at baseline, while at Week 24, significantly lower levels of total cholesterol, LDL cholesterol and triglycerides were observed. The mean SBP also improved by an average of $-6.1 \pm 16.1 \mathrm{mmHg}$, suggesting that patients may have initiated lifestyle changes during the study. As expected, mean body weight increased in the entire subgroup, primarily due to an increase $(\sim 2.0 \mathrm{~kg})$ in insulin-naïve patients following the start of insulin therapy.

Fluctuating blood glucose levels and the complications associated with T2D can significantly affect patients' well-being [14]. However, following 24 weeks of BIAsp 30 therapy, patient QoL, assessed using the validated EQ-5D questionnaire, improved noticeably from baseline levels. It is possible that the demonstrated improvements in blood glucose and lipid levels and the low incidence of hypoglycaemia may have contributed to the greater positive patient responses at Week 24 .

This sub-analysis is subject to certain limitations of the non-interventional design of the $\mathrm{A}_{1}$ chieve study. The study lacked a control arm. Concomitant medication and dietary intake were not controlled and data collection was largely based on patient recall, diaries or self-reported information. The incidence of hypoglycaemia was collected based on the patients' recall of the past 4 weeks prior to the study visit, which may have led to an underestimation of the actual occurrence rate of hypoglycaemic events. Nevertheless, this study provided an opportunity to evaluate treatment strategies for T2D in routine clinical care in Jordan. The results of this subanalysis demonstrate the safety and effectiveness of BIAsp 30 in a setting that is close to real life and in a patient group not restricted by strict selection criteria. These results can also provide evidence for framing clinical poli- 
cies in Jordan. In summation, starting BIAsp 30 therapy improved glycaemic control and was not associated with any issues of tolerability or safety in this Jordanian subgroup.

\section{Acknowledgements}

The authors would like to thank all participants who provided data, and all investigators involved in the $A_{1}$ chieve study. The authors would like to thank Chunduo Shen of Novo Nordisk for providing statistical analysis. The authors would also like to thank Anjali Philip of Cognizant Technology Solutions for writing assistance, funded by Novo Nordisk.

This study was sponsored by Novo Nordisk. The sponsor took part in the development of the protocol, the process of data collection and analysis, funding of medical writing services, and in reviewing the manuscript, but not in participant selection, choice of therapies (study or otherwise), provision of therapies including insulin or continuing clinical management of the participants.

\section{Conflict of Interest}

Jihad Haddad is an advisory board member for Novo Nordisk and Merck, and is on the speaker's bureau for Novo Nordisk, Merck, Novartis, Astra Zeneca, Merck Sharp \& Dohme, and Menarini. Levent Sandalci is employed by Novo Nordisk. Fares H. Haddad, Rashad Nasser, Abdel-Ellah Al-Shudifat, Firas Abbas Annavi and Moawia Al-Kilani have no conflicts of interest to declare.

\section{References}

[1] Rawal, L.B., Tapp, R.J., Williams, E.D., Chan, C., Yasin, S. and Oldenburg, B. (2012) Prevention of Type 2 Diabetes and Its Complications in Developing Countries: A Review. International Journal of Behavioral Medicine, 19, 121-133. http://dx.doi.org/10.1007/s12529-011-9162-9

[2] International Diabetes Federation (2011) International Diabetes Federation (IDF) Diabetes Atlas. 5th Edition, IDF, Brussels.

[3] Zindah, M., Belbeisi, A., Walke, H. and Mokdad, A.H. (2008) Obesity and Diabetes in Jordan: Findings from the Behavioral Risk Factors Surveillance System, 2004. Preventing Chronic Disease, 5, A17.

[4] Khattab, M., Khader, Y.S., Al-Khawaldeh, A. and Ajlouni, K. (2010) Factors Associated with Poor Glycemic Control among Patients with Type 2 Diabetes. Journal of Diabetes and Its Complications, 24, 84-89. http://dx.doi.org/10.1016/j.jdiacomp.2008.12.008

[5] Inzucchi, S.E., Bergenstal, R.M., Buse, J.B., Diamant, M., Ferrannini, E., Nauck, M., et al. (2012) Management of Hyperglycaemia in Type 2 Diabetes: A Patient-Centered Approach. Position Statement of the American Diabetes Association (ADA) and the European Association for the Study of Diabetes (EASD). Diabetologia, 55, 1577-1596. http://dx.doi.org/10.1007/s00125-012-2534-0

[6] Brunton, S. (2009) Safety and Effectiveness of Modern Insulin Therapy: The Value of Insulin Analogs. Consultant, 49, S13-S19.

[7] Halimi, S., Raskin, P., Liebl, A., Kawamori, R., Fulcher, G. and Yan, G. (2005) Efficacy of Biphasic Insulin Aspart in Patients with Type 2 Diabetes. Clinical Therapeutics, 27, S57-S74. http://dx.doi.org/10.1016/j.clinthera.2005.11.021

[8] Davidson, J., Vexiau, P., Cucinotta, D., Vaz, J. and Kawamori, R. (2005) Biphasic Insulin Aspart 30: Literature Review of Adverse Events Associated with Treatment. Clinical Therapeutics, 27, S75-S88. http://dx.doi.org/10.1016/j.clinthera.2005.11.022

[9] Davidson, J.A., Liebl, A., Christiansen, J.S., Fulcher, G., Ligthelm, R.J., Brown, P., et al. (2009) Risk for Nocturnal Hypoglycemia with Biphasic Insulin Aspart 30 Compared with Biphasic Human Insulin 30 in Adults with Type 2 Diabetes Mellitus: A Meta-Analysis. Clinical Therapeutics, 31, 1641-1651. http://dx.doi.org/10.1016/j.clinthera.2009.08.011

[10] Liebl, A., Prusty, V., Valensi, P., Kawamori, R., Christiansen, J.S., Palmer, A.J., Balschmidt, P., Ligthelm, R. and Mohan, V. (2012) Ten Years of Experience with Biphasic Insulin Aspart 30: From Drug Development to the Latest Clinical Findings. Drugs, 72, 1495-1520. http://dx.doi.org/10.2165/11635490-000000000-00000

[11] Home, P., Naggar, N.E., Khamseh, M., Gonzalez-Galvez, G., Shen, C., Chakkarwar, P., et al. (2011) An Observational Non-Interventional Study of Patients with Diabetes Beginning or Changed to Insulin Analogue Therapy in Non-Western Countries: The $\mathrm{A}_{1}$ chieve Study. Diabetes Research and Clinical Practice, 94, 352-363. http://dx.doi.org/10.1016/j.diabres.2011.10.021

[12] Stratton, I.M., Adler, A.I., Neil, H.A., Matthews, D.R., Manley, S.E., Cull, C.A., et al. (2000) Association of Glycae- 
mia with Macrovascular and Microvascular Complications of Type 2 Diabetes (UKPDS 35): Prospective Observational Study. British Medical Journal, 321, 405-412. http://dx.doi.org/10.1136/bmj.321.7258.405

[13] Abdel-Aal, N.M., Ahmad, A.T., Froelicher, E.S., Batieha, A.M., Hamza, M.M. and Ajlouni, K.M. (2008) Prevalence of Dyslipidemia in Patients with Type 2 Diabetes in Jordan. Saudi Medical Journal, 29, 1423-1428.

[14] Braun, A., Sämann, A., Kubiak, T., Zieschang, T., Kloos, C., Müller, U.A., et al. (2008) Effects of Metabolic Control, Patient Education and Initiation of Insulin Therapy on the Quality of Life of Patients with Type 2 Diabetes Mellitus. Patient Counselling and Health Education, 73, 50-59. http://dx.doi.org/10.1016/j.pec.2008.05.005 
Scientific Research Publishing (SCIRP) is one of the largest Open Access journal publishers. It is currently publishing more than 200 open access, online, peer-reviewed journals covering a wide range of academic disciplines. SCIRP serves the worldwide academic communities and contributes to the progress and application of science with its publication.

Other selected journals from SCIRP are listed as below. Submit your manuscript to us via either submit@scirp.org or Online Submission Portal.
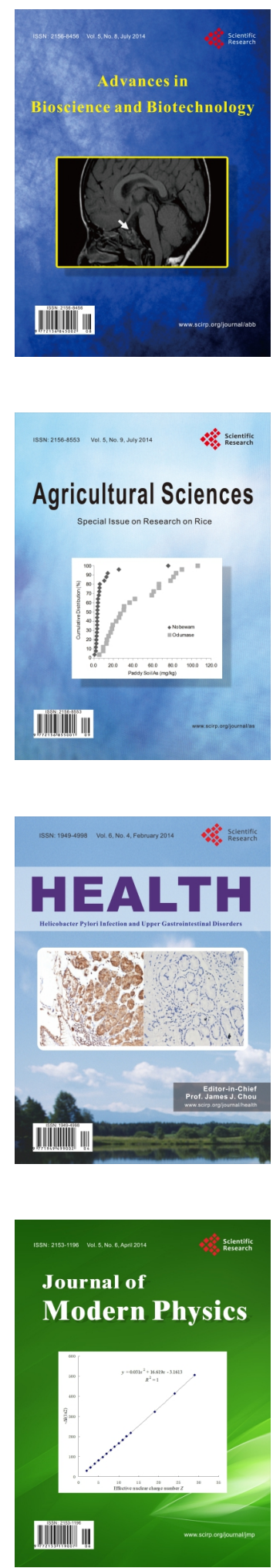
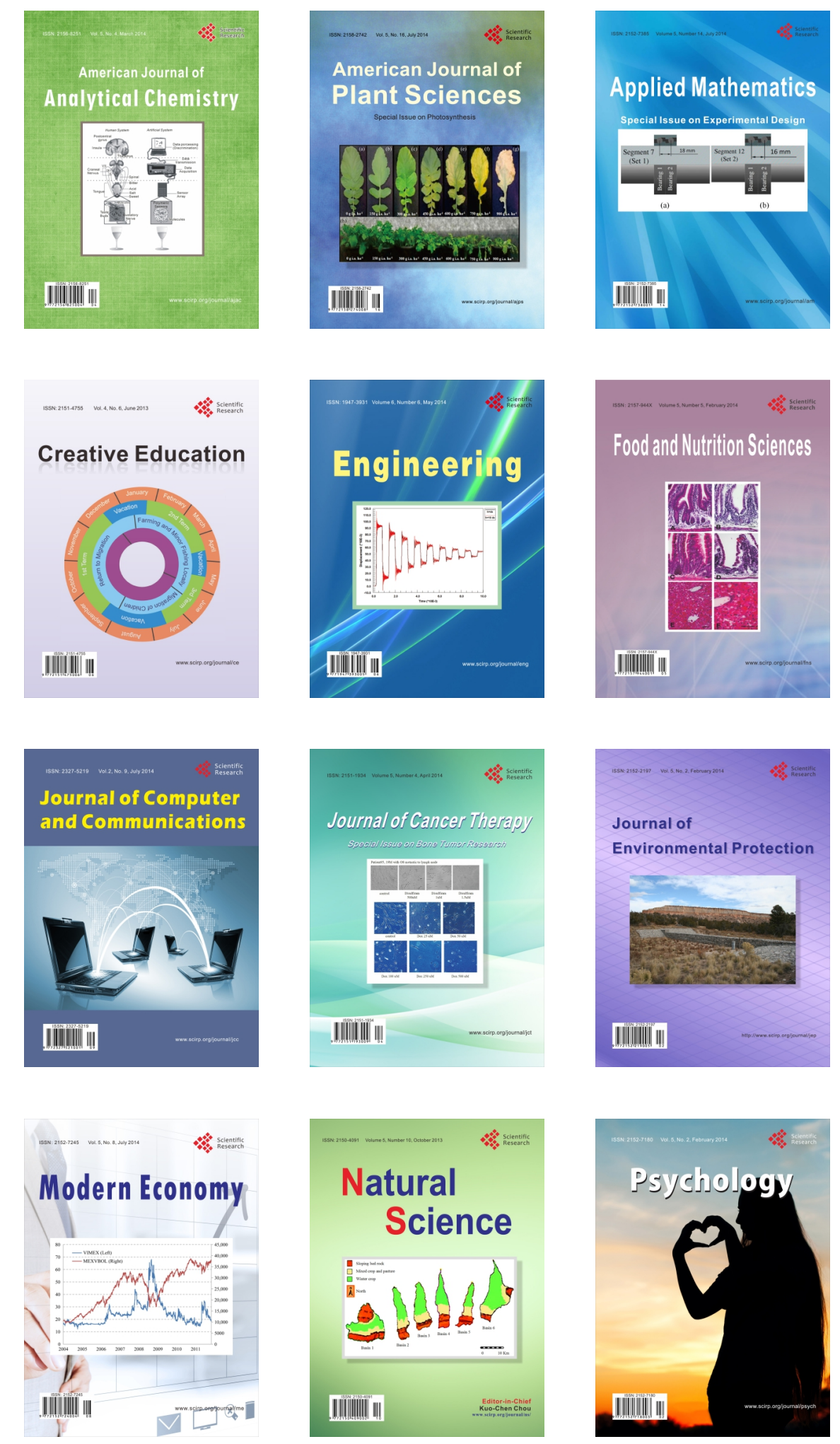